\title{
Corrigendum
}

\section{Corrigendum to "Excretory Function of Intestinal Tract Enhanced in Kidney Impaired Rats Caused by Adenine"}

\author{
Yu Yun $\mathbb{D}^{1,2}$ Tao Gao, ${ }^{1}$ Yue Li, ${ }^{1}$ Zhiyi Gao, ${ }^{1}$ Jinlian Duan, ${ }^{1}$ Hua Yin, ${ }^{1}$ and Weigang Duan $\mathbb{D I D}^{1}$ \\ ${ }^{1}$ Kunming Key Laboratory of Molecular Biology for Sinomedicine, Faculty of Basic Medicine, \\ Yunnan University of Traditional Chinese Medicine, Kunming 650500, China \\ ${ }^{2}$ School of Basic Medicine, Kunming Medical University, Kunming 650500, China \\ Correspondence should be addressed to Weigang Duan; deardwg@126.com
}

Received 5 October 2020; Accepted 5 October 2020; Published 23 October 2020

Copyright $\odot 2020 \mathrm{Yu}$ Yun et al. This is an open access article distributed under the Creative Commons Attribution License, which permits unrestricted use, distribution, and reproduction in any medium, provided the original work is properly cited.

In the article titled "Excretory Function of Intestinal Tract Enhanced in Kidney Impaired Rats Caused by Adenine" [1], there were two errors, which should be corrected as follows:

(i) The gender of rats used for the experiment was wrongly mentioned as "female." This should be corrected as "male."

(ii) In Figure 4 legend, the value of serum uric acid in normal rats " $21.93 \pm 6.98 \mu \mathrm{g} / \mathrm{ml}$ " should be corrected to " $20.93 \pm 6.98 \mu \mathrm{g} / \mathrm{ml}$."

The authors would like to apologize for any inconvenience caused.

\section{References}

[1] Y. Yun, T. Gao, Y. Li et al., "Excretory function of intestinal tract enhanced in kidney impaired rats caused by adenine," The Scientific World Journal, vol. 2016, Article ID 2695718, 7 pages, 2016. 